\title{
Universiteit
}

Leiden

The Netherlands

\section{H NMR spectroscopy of the binuclear CU(ll) active site of streptomyces antibioticus tyrosinase}

Bubacco, L.; Salgado, J.; Tepper, W.J.W.; Vijgenboom, E.; Canters, G.W.

\section{Citation}

Bubacco, L., Salgado, J., Tepper, W. J. W., Vijgenboom, E., \& Canters, G. W. (1999). 1H NMR spectroscopy of the binuclear CU(ll) active site of streptomyces antibioticus tyrosinase. Febs Letters, 442(2-3), 215-220. doi:10.1016/S0014-5793(98)01662-7

Version: Publisher's Version

License: $\quad$ Leiden University Non-exclusive license

Downloaded from: https://hdl.handle.net/1887/3209718

Note: To cite this publication please use the final published version (if applicable). 


\title{
${ }^{1} \mathrm{H}$ NMR spectroscopy of the binuclear $\mathrm{Cu}(\mathrm{II})$ active site of Streptomyces antibioticus tyrosinase
}

\author{
Luigi Bubacco ${ }^{1}$, Jesús Salgado², Armand W.J.W. Tepper, Erik Vijgenboom, \\ Gerard W. Canters* \\ Leiden Institute of Chemistry, Gorlaeus Laboratories, Leiden University, P.O. Box 9502, 2300 RA Leiden, The Netherlands
}

Received 7 December 1998

\begin{abstract}
The $600 \mathrm{MHz}{ }^{1} \mathrm{H}$ NMR spectrum of tyrosinase (31 kDa) of Streptomyces antibioticus in the oxidized, chloridebound form is reported. The downfield part of the spectrum (15$55 \mathrm{ppm}$ ) exhibits a large number of paramagnetically shifted signals. The paramagnetism is ascribed to a thermally populated triplet state. The signals derive from six histidines binding to the metals through their $\mathrm{N \varepsilon}$ atoms. There is no evidence for endogenous bridges. The exchange coupling, $-2 J$, amounts to $298 \mathrm{~cm}^{-1}$. In the absence of chloride the peaks broaden. This is ascribed to a slowing down of the electronic relaxation. The exchange coupling decreases to $-2 J=103 \mathrm{~cm}^{-1}$.
\end{abstract}

(c) 1999 Federation of European Biochemical Societies.

Key words: Paramagnetic; Phenoloxidase; Oxygenase; Exchange; Copper protein; Curie

\section{Introduction}

One of the unsolved problems in the biological function of copper is the mechanism of action of tyrosinase. The enzyme contains a binuclear, so-called type- $3 \mathrm{Cu}$ center in its catalytically active site, catalyzes the conversion of monophenols and $o$-diphenols into quinones and occurs widely in nature, from bacteria to fungi, from plants to man. Despite its fundamental biological and biomedical importance no structure of the active site, let alone of a whole enzyme, has been reported. The only structural information available so far is based on early enzymological and spectroscopic work (see [1,2] for recent reviews), and on primary sequence comparisons between tyrosinases and hemocyanins ([3]; reviewed in [4]). From this it has been surmised that the two copper atoms in the active site of tyrosinase might each be coordinated by three histidines, but direct and definitive proof has been lacking.

Structural information on the active site is a definite requirement for understanding the mechanistic properties of any enzyme in detail. It has transpired from studies of small $\mathrm{Cu}_{2}$ containing model compounds that paramagnetic NMR can be a helpful tool in the study of the magnetic and structural properties of $\mathrm{Cu}_{2}$ sites [5-11]. Most of these studies dealt with compounds which, in the oxidized $[\mathrm{Cu}(\mathrm{II})-\mathrm{Cu}(\mathrm{II})]$ form, have a ground state which is diamagnetic due to an antiferro-

\footnotetext{
*Corresponding author. Fax: (31) (71) 5274349.

E-mail: canters@chem.leidenuniv.nl

${ }^{1}$ Present address: Department of Biology, University of Padova, Via Trieste 75, 35131 Padua, Italy.

${ }^{2}$ Present address: FSU Jena, Institut für Molekularbiologie, Winzerlaer Str. 10, Jena, Germany.
}

magnetic coupling between the spins on the two copper centers as reflected in their EPR silence at low temperatures. Such an antiferromagnetic coupling requires the presence of a superexchange pathway associated with a bridging ligand [12]. The fact that paramagnetically shifted NMR signals can still be observed in these compounds is due to the presence of a paramagnetic $(S=1)$ excited triplet state which is accessible at room temperature. Recent studies of the $\mathrm{Cu}_{2}$ center in proteins containing a mixed-valence $\mathrm{Cu}_{\mathrm{A}}$ site or a binuclear $\mathrm{Cu}$ substituted $\mathrm{Zn}$ site have demonstrated that paramagnetic NMR can also be applied to metalloproteins containing a binuclear $\mathrm{Cu}$ site [13-16].

Here we report on the ${ }^{1} \mathrm{H}$ NMR spectrum of tyrosinase from Streptomyces antibioticus in the oxidized [Cu(II)$\mathrm{Cu}(\mathrm{II})]$ state in the presence and absence of chloride. It appears that despite its size $(31 \mathrm{kDa})$ the protein gives well resolved paramagnetic spectra from which the ligands to the $\mathrm{Cu}_{2}$ site can be identified as six histidines. There is no evidence for a protein-derived bridging side chain. The temperature dependence of the paramagnetic shifts provides for the magnitude of the exchange coupling between the unpaired spins on the two $\mathrm{Cu}(\mathrm{II})$ ions. The presence of chloride in the solution has a marked influence on the spectrum: the NMR signals exhibit appreciable sharpening and the exchange coupling increases drastically. Apparently chloride binds at or close to the active site. To our knowledge this is the first observation of paramagnetic NMR of an enzyme containing a natural type-3 $\mathrm{Cu}$ site. The observations hold promise for further structural and mechanistic studies.

\section{Materials and methods}

\subsection{Expression and purification of protein}

The DNA fragment containing the gene encoding tyrosinase from S. antibioticus has been cloned before into plasmid pIJ703 [17]; the plasmid was received as a kind gift from Prof. Dr. E. Katz. The plasmid was transformed to S. lividans by standard methods [18] and brought to expression in medium containing $30 \mathrm{~g} / \mathrm{l}$ Oxoid soya broth, $10 \% \mathrm{w} / \mathrm{v}$ sucrose and $5 \mu \mathrm{g} / \mathrm{ml}$ thiostrepton. The medium, which contained the enzyme, was separated from the cell mass by centrifugation. Protein was purified according to published procedures [1921]. Purity was checked on SDS-PAGE. Activity was assayed according to standard methods [21].

\subsection{NMR spectroscopy}

NMR samples of fresh protein $(0.6 \mathrm{mM})$ were prepared in $100 \mathrm{mM}$ phosphate buffer $\mathrm{pH} 6.8$, either in $\mathrm{H}_{2} \mathrm{O} / \mathrm{D}_{2} \mathrm{O}(95 / 5 \mathrm{v} / \mathrm{v})$ or in $99.98 \%$ $\mathrm{D}_{2} \mathrm{O}$. When needed, chloride was added to the sample in the form of $\mathrm{NaCl}$. The protein as isolated usually is present for over $90 \%$ in the met $[\mathrm{Cu}(\mathrm{II})-\mathrm{Cu}(\mathrm{II})]$ form. During the concentration procedure that was used for the preparation of the NMR sample, the protein converted further to the met form. Protein concentration was determined from the absorbance at $280 \mathrm{~nm}\left(\varepsilon=8.2 \times 10^{4} \mathrm{M}^{-1} \mathrm{~cm}^{-1}\right)$ [21].

${ }^{1} \mathrm{H}$ NMR spectra were recorded on a Bruker DMX-600 NMR 
spectrometer with the use of a super-WEFT pulse sequence [22] (interpulse delay: $80 \mathrm{~ms}$; repetition rate: $6 \mathrm{~s}^{-1}$; spectral width: $150 \mathrm{ppm}$ ). A total of 16000 free induction decays were acquired, Fourier transformed with the use of an exponential window $(\mathrm{LB}=50)$ and baseline corrected with the use of Bruker provided software. 1D NOEs were measured according to standard techniques $[23,24]$.

Spin-lattice relaxation times were measured with a non-selective $180-\tau-90$ pulse sequence and by observing the response as a function of $\tau$. Spin-spin relaxation times were derived from the half-width at half-height of the NMR signals.

\section{Results}

Examples of $600 \mathrm{MHz}{ }^{1} \mathrm{H}$ NMR spectra of met-tyrosinase in $\mathrm{H}_{2} \mathrm{O}$ at $280 \mathrm{~K}$ in the absence (A) and presence (B) of chloride are presented in Fig. 1. The peaks observed in the spectrum of the chloride-free sample are broader than the peaks observed in the chloride-containing sample. The downfield part of the spectrum $(>14 \mathrm{ppm})$ in both cases contains a rich fine structure of paramagnetically shifted peaks, which have been labeled $\mathrm{a}-\mathrm{n}$ (main species), and $\mathrm{a}^{1}-\mathrm{e}^{1}$ (minor species) in the spectrum of the chloride containing sample, and 1-9 in the chloride-free sample.

In an attempt to assign the paramagnetically shifted peaks, first the H-exchange behavior of the samples was studied. The effect of changing the solvent is illustrated in Fig. 2 where the spectra recorded on samples in $\mathrm{H}_{2} \mathrm{O}$ and $\mathrm{D}_{2} \mathrm{O}$ are compared. The peaks that disappear in the $\mathrm{D}_{2} \mathrm{O}$ samples have been marked by asterisks. In the spectrum of the chloride-containing sample five sharp signals ( $a, b, d, g$ and $\mathrm{m}$ ) disappear within hours while a sixth sharp peak, e, also disappears but at a much slower rate. Clearly the first five signals correspond to protons that readily exchange with bulk water while the sixth exchangeable proton is less accessible or is stabilized in the protein structure. In a similar way a number of peaks were found to disappear from the spectrum of the chloridefree tyrosinase upon incubation of the protein in $\mathrm{D}_{2} \mathrm{O}$ (peaks 1,2 and 6). Since the spectrum of the chloride-containing
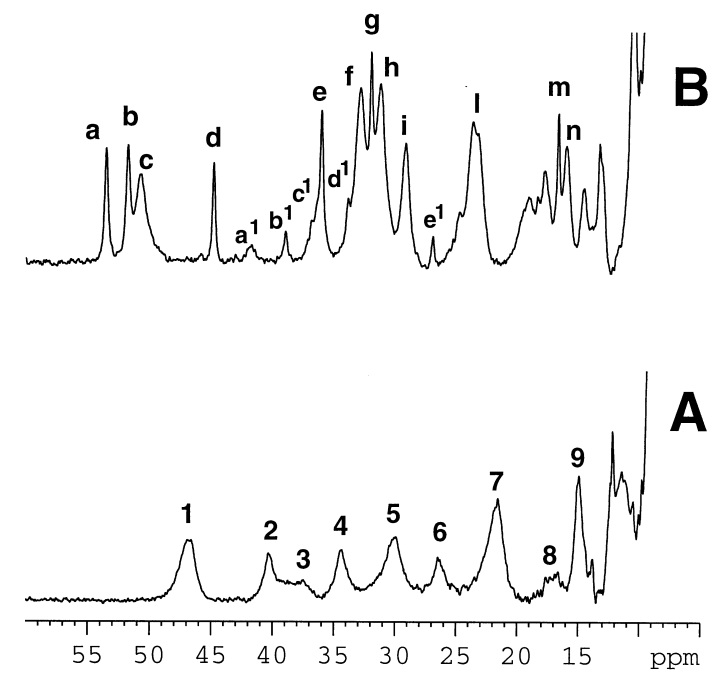

Fig. 1. Downfield region (10-55 ppm) of the $600 \mathrm{MHz}{ }^{1} \mathrm{H}$ NMR spectra of a $0.6 \mathrm{mM}$ solution of $S$. antibioticus met-tyrosinase in $\mathrm{H}_{2} \mathrm{O}(100 \mathrm{mM}$ phosphate, $\mathrm{pH} 8.6)$, at $280 \mathrm{~K}$ in the absence (A) and presence $(B)$ of chloride $(500 \mathrm{mM})$. The spectra were recorded with a super-WEFT sequence. The peaks of the chloride-free and chloride-containing sample have been labeled $1-10$ (A) and $a-n, a^{1}-e^{1}$ (B), respectively, as discussed in the text.

sample is better resolved than that of the chloride-free sample further assignment efforts were concentrated on the former spectrum.

The six paramagnetically shifted peaks in the spectrum of the chloride-containing sample that disappear upon incubation in $\mathrm{D}_{2} \mathrm{O}$ were used as starting points for the second step in the assignment procedure. By means of a series of 1D NOE experiments [24-26] these peaks could be correlated with a number of other paramagnetically shifted peaks. As an example the NOE connectivities within the pairs of peaks a/i, g/l and $\mathrm{b}, \mathrm{d} / \mathrm{h}$ are shown in Fig. 3. Altogether six pairs of peaks,

Table 1

Paramagnetic signals in chloride-bound met-tyrosinase

\begin{tabular}{|c|c|c|c|c|c|c|}
\hline$\delta^{\mathrm{a}}(\mathrm{ppm})$ & $T_{1}{ }^{\mathrm{b}}(\mathrm{ms})$ & $\mathrm{D}_{2} \mathrm{O}$ exchange & Integrated intensity ${ }^{c}$ & NOE to ${ }^{\mathrm{d}}$ signal & \multicolumn{2}{|c|}{ Assignment ${ }^{\mathrm{e}}$} \\
\hline (a) 49.59 & 23.6 & yes & $0.9(1)$ & $\mathrm{i}$ & His $\mathrm{A}$ & $\mathrm{N}^{\delta 1} \mathrm{H}$ \\
\hline (b) 47.94 & 16.9 & yes & $2.1(1)$ & $\mathrm{h}$ & His B & $\mathrm{N}^{\delta 1} \mathrm{H}$ \\
\hline (c) 47.17 & 6.6 & no & $2.1(1)$ & - & His & $\mathrm{C}^{\delta 2} \mathrm{H}$ \\
\hline (d) 41.43 & 26.5 & yes & 0.6 (1) & $\mathrm{h}$ & His $\mathrm{C}$ & $\mathrm{N}^{\delta 1} \mathrm{H}$ \\
\hline (e) 33.46 & 18.7 & yes & $1.5(1)$ & $\mathrm{n}$ & His D & $\mathrm{N}^{\delta 1} \mathrm{H}$ \\
\hline (f) 30.71 & 5.5 & no & $10.2(2)$ & - & $\begin{array}{l}\text { His } \\
\text { His }\end{array}$ & $\begin{array}{l}\mathrm{C}^{\delta 2} \mathrm{H} \\
\mathrm{C}^{\delta 2} \mathrm{H}\end{array}$ \\
\hline (g) 29.72 & 26.7 & yes & $10.2(1)$ & 1 & His $\mathrm{E}$ & $\mathrm{N}^{\delta 1} \mathrm{H}$ \\
\hline (h) 29.05 & 5.6 & no & $10.2(3)^{\mathrm{f}}$ & $b, d$ & $\begin{array}{l}\text { His B } \\
\text { His C } \\
\text { His }\end{array}$ & $\begin{array}{l}\mathrm{C}^{\varepsilon 1} \mathrm{H} \\
\mathrm{C}^{\varepsilon 1} \mathrm{H} \\
\mathrm{C}^{\delta 2} \mathrm{H}\end{array}$ \\
\hline (i) 27.12 & 4.7 & no & $10.2(2)$ & $\mathrm{a}, \mathrm{m}$ & $\begin{array}{l}\text { His A } \\
\text { His F }\end{array}$ & $\begin{array}{l}\mathrm{C}^{\varepsilon 1} \mathrm{H} \\
\mathrm{C}^{\varepsilon 1} \mathrm{H}\end{array}$ \\
\hline (l) 21.90 & 4.3 & no & $3.0(3)$ & $\mathrm{g}$ & $\begin{array}{l}\text { His E } \\
\text { His } \\
\text { His }\end{array}$ & $\begin{array}{l}\mathrm{C}^{\varepsilon 1} \mathrm{H} \\
\mathrm{C}^{\delta 2} \mathrm{H} \\
\mathrm{C}^{\delta 2} \mathrm{H}\end{array}$ \\
\hline (m) 15.63 & 24.5 & yes & $0.9(1)$ & $\mathrm{i}$ & His $\mathrm{F}$ & $\mathrm{N}^{\delta 1} \mathrm{H}$ \\
\hline (n) 14.92 & $\mathrm{nc}$ & no & $\mathrm{nc}$ & $\mathrm{e}$ & His D & $\mathrm{C}^{\varepsilon 1} \mathrm{H}$ \\
\hline
\end{tabular}

${ }^{\mathrm{a}}$ Hyperfine shift.

${ }^{\mathrm{b}}$ Values obtained from an inversion recovery experiment $[23,24]$.

${ }^{\mathrm{c}}$ Integrals not corrected for minor species; values in parentheses: tentative assignment of intensity.

${ }^{\mathrm{d}}$ Steady-state 1D NOEs.

${ }^{\mathrm{e}}$ The ligand histidines are labeled by capitals; assignment of $\mathrm{His} \mathrm{C}^{\delta 2} \mathrm{H}$ signals is tentative.

${ }^{\mathrm{f}}$ Intensity particularly sensitive to baseline variation. 

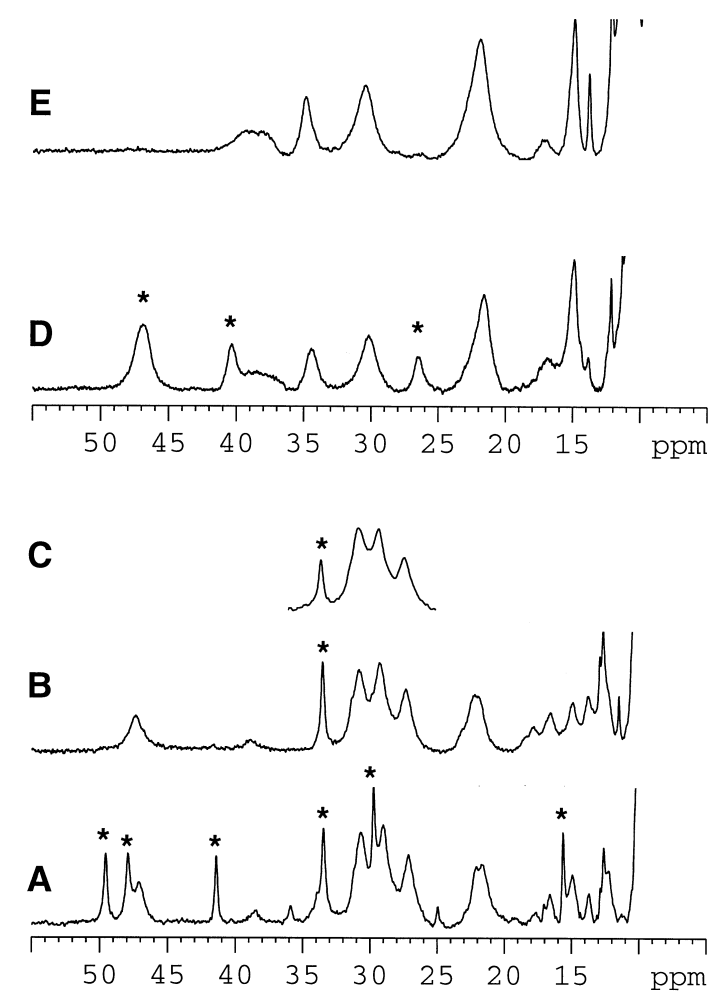

Fig. 2. ${ }^{1} \mathrm{H}$ NMR spectrum of $S$. antibioticus met-tyrosinase in the presence of chloride in $\mathrm{H}_{2} \mathrm{O}$ (A) and in $\mathrm{H}_{2} \mathrm{O} / \mathrm{D}_{2} \mathrm{O}(10 / 90 \mathrm{v} / \mathrm{v})$ measured $2 \mathrm{~h}(\mathrm{~B})$ and 30 days (stored at $\left.4^{\circ} \mathrm{C}\right)(\mathrm{C})$ after preparation of the sample, illustrating the sensitivity of the asterisked peaks to hydrogen exchange. Spectra D and $\mathrm{E}$ are the equivalents of spectra $\mathrm{A}$ and $\mathrm{B}$, respectively, but for the chloride-free sample. Experimental conditions as in Fig. 1.

labeled A-F, could be identified in this way, as shown in Fig. 4 and Table 1 . No additional NOEs were observed.

The $T_{1}$ values have been measured for the peaks a-m and are collected in Table 1. They divide into two groups: the signals deriving from the exchangeable protons have long relaxation times (17-27 ms) while the rest relax with much shorter characteristic times (4-6 ms). A similar division into long (7-15 ms; peaks $1,2,4,6,9)$ and short (1-3 ms; peaks 3 , $5,7,8)$ relaxation times is observed for the chloride-free sample. The temperature dependence of the resonance positions of a number of selected peaks is shown in Fig. 5 for the chloridecontaining sample.

The intensities of the peaks in the $15-50 \mathrm{ppm}$ range have been obtained by straightforward integration, although uncertainty about the position of the base line precluded a high accuracy of the integrals. The data are listed in Table 1 with a partition of intensities over the labeled peaks as indicated by the numbers in parentheses. The partition is tentative and was made with the following considerations in mind. Firstly, the intensity of the minor species visible in the spectrum (see above) amounts to about $25 \%$ of the main species. In crowded regions of the spectrum (like the 26-34 ppm region) where the two species were not resolved, the total intensity was corrected, therefore, by one fifth. Secondly, some ambiguities in the assignment of intensities could be resolved by taking into account the data observed for the $\mathrm{D}_{2} \mathrm{O}$ sample. Moreover, the peaks corresponding with the main and the minor species shift differently with temperature; thus, a few peaks could be resolved by varying the temperature, which also helped in assigning intensities. Finally, as observed often in paramagnetic NMR spectra, the water exchangeable peaks (which also happen to be the peaks with long $T_{1} \mathrm{~s}$ ) integrate to intensities less than 1 . These peaks have been assigned an intensity of 1 .

\section{Discussion}

The magnitude of the shifts in the $15-50$ ppm region in Fig. 1 makes it clear that the $\mathrm{Cu}_{2}$ center in tyrosinase carries appreciable paramagnetism. As met-tyrosinase is EPR-silent at low temperatures, this means that there is a thermally accessible paramagnetic state at room temperature which provides for a substantial amount of paramagnetism. Moreover, the paramagnetic shifts are so large that the signals can only derive from ligands to the $\mathrm{Cu}_{2}$ center. Thus, the downfield region of the ${ }^{1} \mathrm{H}$ NMR spectrum of tyrosinase provides a fingerprint of the active site. The important question is to establish the nature of the ligands. For this we consider the chloride-containing sample.

The customary procedure when searching for signals of metal ligands in the NMR spectrum of a paramagnetic metalloprotein is to look for water-exchangeable protons in the paramagnetically shifted region, since they identify the ringNH signals of ligand histidines and (in rare cases) signals from backbone amide protons that are sufficiently close to the para-
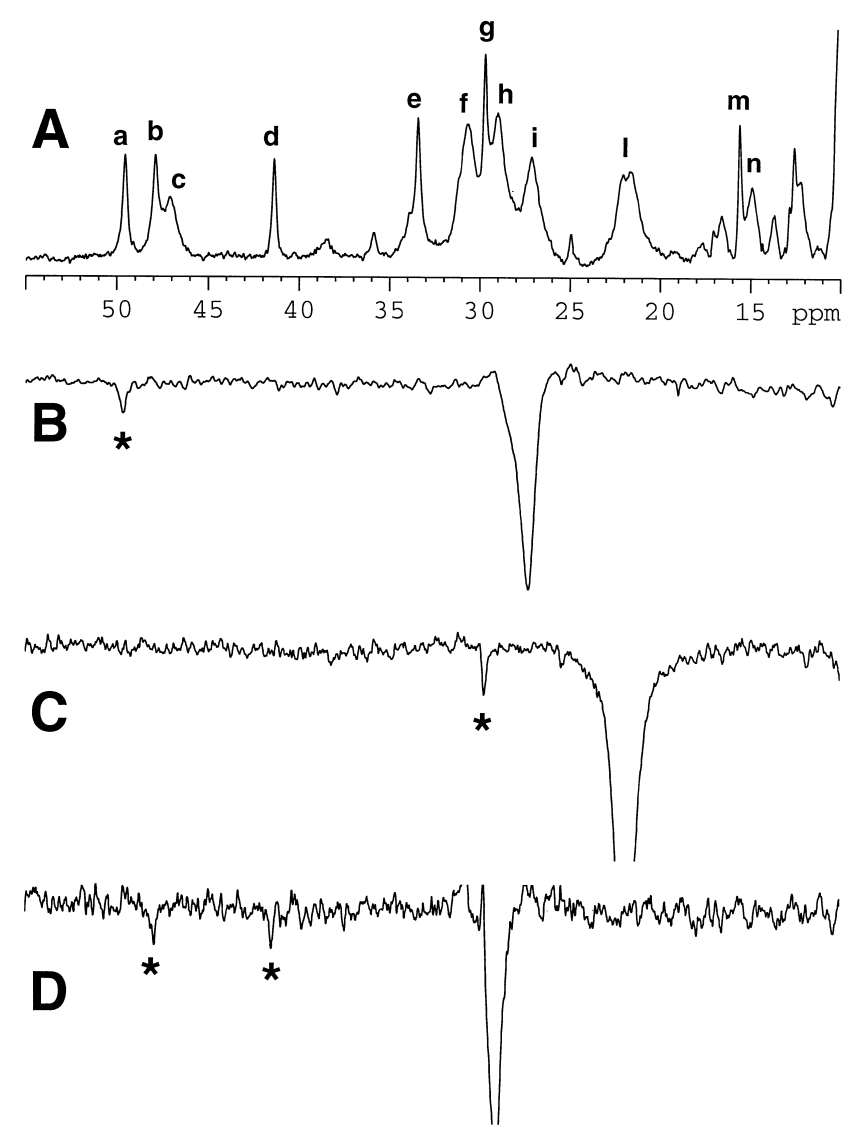

Fig. 3. Examples of $1 \mathrm{D}$ NOE traces observed on a sample of 0.6 $\mathrm{mM}$ S. antibioticus met-tyrosinase in $\mathrm{H}_{2} \mathrm{O}$ at $280 \mathrm{~K}$. The asterisks in the difference spectra B-D mark positions in the spectrum where a NOE effect was observed. Further experimental conditions as in Fig. 1. 


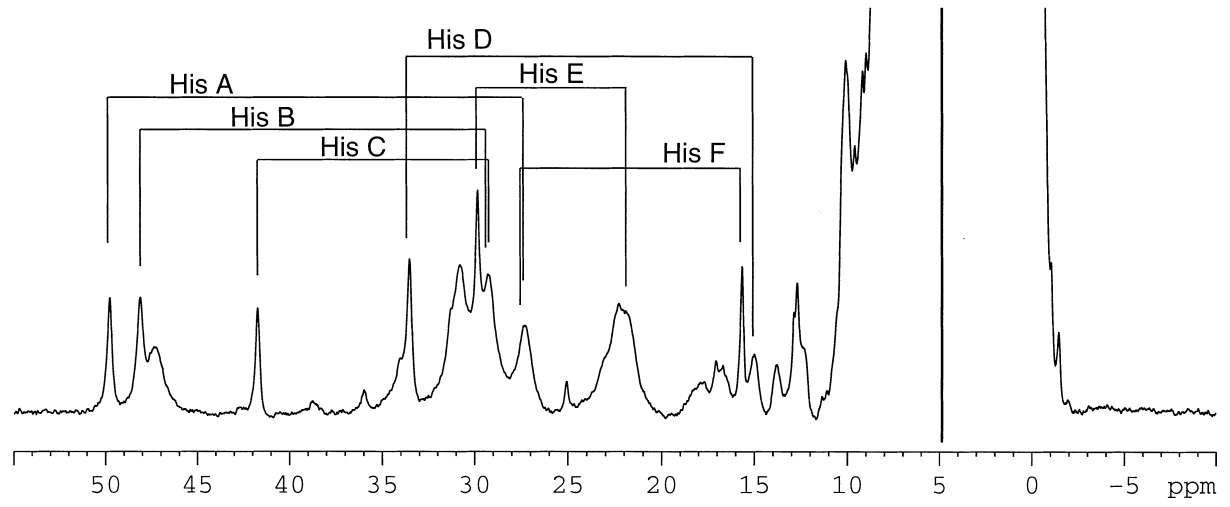

Fig. $4 .{ }^{1} \mathrm{H}$ NMR spectrum of $S$. antibioticus met-tyrosinase (see also Fig. 1), in which the observed pairwise NOE connectivities have been indicated. The pairs have been labeled A-F (see also Table 1).

magnetic center to carry noticeable spin density [23,27]. The data in Fig. 2 and in Table 1 demonstrate that there are six of these protons, consistent with their assignment to the exchangeable ring protons of six ligand histidines (see further evidence below).

Relaxation data in combination with NOE data in principle allow for establishing the mode of coordination of a histidine, as has been demonstrated by Bertini, Luchinat and coworkers [26-29]. The relaxation of protons belonging to histidine ligands of a $\mathrm{Cu}(\mathrm{II})$ center is mainly determined by the throughspace magnetic dipolar interaction between the nucleus and the unpaired electron of the copper [29]. The elements of the tensor describing this interaction are obtained by integrating the dipolar interaction operator over the wave function of the unpaired electron [30,31]. The relaxation rates are then proportional to the trace of the squared tensor [30,32,33]. In practice the tensor elements are difficult to calculate and one often resorts to approximating the electron by a point dipole located at the paramagnetic center, which results in a $1 / R^{6}$ dependence of the rates on the proton-metal distance, $R$. The relaxation rates, thus, contain information on proton$\mathrm{Cu}$ distances. However, for $\mathrm{Cu}(\mathrm{II})$-histidine systems the point dipole description is a poor approximation, as Bertini and coworkers have shown, and extracting distance information from the relaxation rates is not straightforward [26,27]. For instance, $T_{1}$ relaxation times for ring protons of histidines connected to a $\mathrm{Cu}(\mathrm{II})$ center may vary by almost a factor of five, the variation showing only a limited correlation with $R^{6}$. However, although the rates may vary from histidine to histidine, within a particular histidine the ring protons at ortho positions (with respect to the $\mathrm{Cu}$-His bond) usually appear to relax faster than the meta protons [26,34]. Thus $T_{1}$ data can be used as a guide to distinguish ortho from meta protons.

The relaxation and NOE patterns corresponding with a histidine coordinated to a paramagnetic metal through its $\mathrm{N} \delta$ or its $\mathrm{N} \varepsilon$ atom are illustrated in Fig. 6. When six histidines coordinate through their $\mathrm{N} \delta$ atoms to $\mathrm{Cu}$ there will be 12 meta protons, six of which may exchange in $\mathrm{D}_{2} \mathrm{O}$, and six ortho protons, with NOE connectivities as depicted in Fig. 6A. If the coordination is through the $\mathrm{N} \varepsilon$ atoms, there are six meta protons all of which may exchange in $\mathrm{D}_{2} \mathrm{O}$, and 12 ortho protons, with NOE connectivities as depicted in Fig. 6B. Considering the signal intensities, relaxation times, H-exchange behavior and NOE connectivities as gathered in Table 1 and illustrated in Fig. 4, it is clear that coordination of six histidines through their $\mathrm{N} \varepsilon$ atoms is in line with the experimental observations as opposed to coordination through the $\mathrm{N} \delta$ atoms.

The temperature dependence of the paramagnetic shifts in the chloride-containing and chloride-free samples was also measured. As an example the data for the chloride-containing sample are depicted in Fig. 5. The simplest model to account for the temperature variation of the shifts is to assume that a thermally accessible triplet state is located at an energy $-2 J$ above the ground state, where $J$ represents the exchange coupling between the electrons on the two $\mathrm{Cu}$ (II) ions. The temperature dependence of the shifts then is given by

$\delta_{\mathrm{c}}=\frac{2 A}{\hbar} \frac{g \beta H}{k_{\mathrm{B}} T} \frac{\exp \left(2 J / k_{\mathrm{B}} T\right)}{\left[1+3 \exp \left(2 J / k_{\mathrm{B}} T\right)\right]}$

in which $k_{\mathrm{B}}$ is the Boltzmann constant, $\hbar$ the constant of Planck divided by $2 \pi, H$ the externally applied magnetic field,

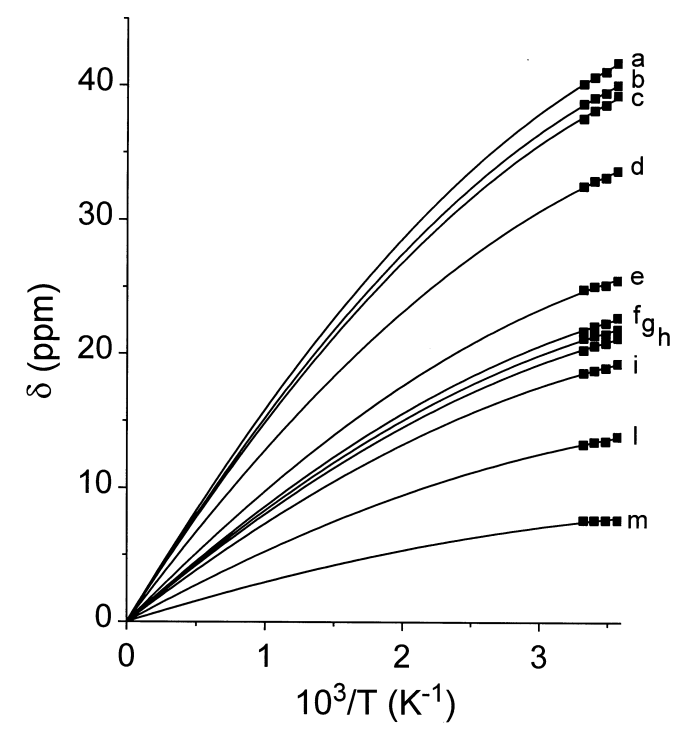

Fig. 5. Curie plot of the contact shifts of the signals in the downfield region of the ${ }^{1} \mathrm{H}$ NMR spectrum of $S$. antibioticus met-tyrosinase as a function of the inverse temperature in the presence of chloride $(500 \mathrm{mM})$. The contact shifts were obtained by subtracting the diamagnetic chemical shift (set at $8 \mathrm{ppm}$ ) from the experimentally measured shifts. Contributions from pseudo-contact interactions were ignored. Other conditions as in Fig. 1. The solid lines represent least squares fits on the basis of Eq. 1 . 

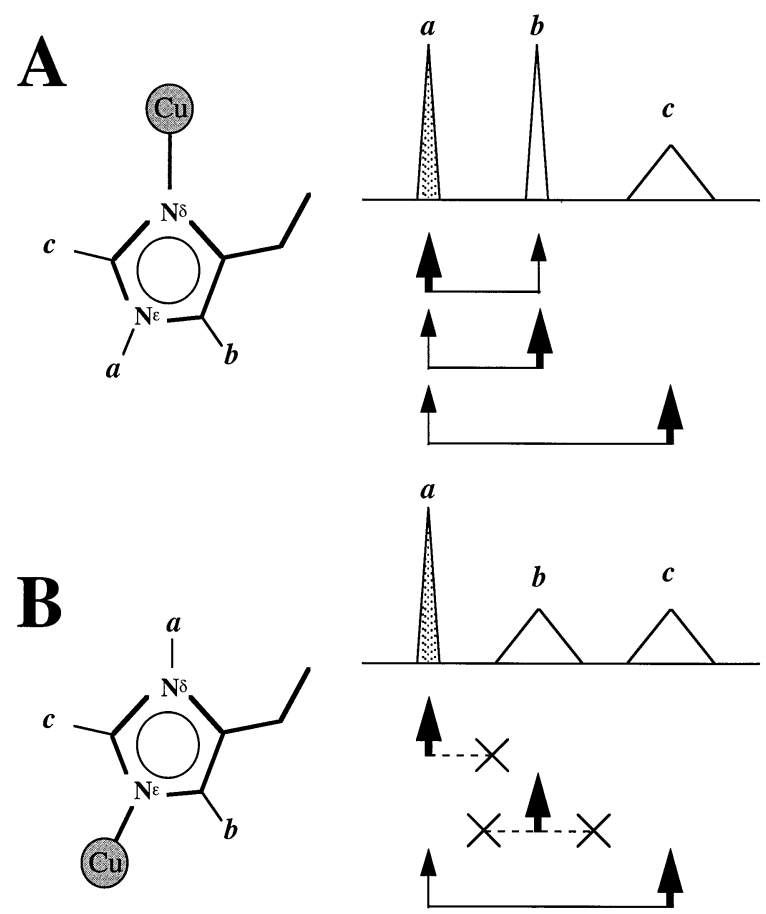

Fig. 6. Schematic representation of the $T_{1}$ relaxation rates and NOE connectivities expected for the ring proton NMR signals of a histidine coordinated to a paramagnetic $\mathrm{Cu}(\mathrm{II})$ ion (resonance positions of signals are arbitrary). Coordination by the histidine $\mathrm{N} \delta$ and $\mathrm{N} \varepsilon$ atoms is depicted in A and B, respectively. For a particular histidine two types of signal can be distinguished: slower relaxing ones (symbolized by sharp triangles) deriving from 'meta' protons ( $a / b$ (A) or $a(\mathrm{~B})$ ), and faster relaxing ones (broad triangles) deriving from 'ortho' protons ( $c$ (A) or $b / c$ (B)). Shaded peaks refer to exchangeable protons. Observable NOE connectivities are indicated by thin lines. A heavy arrow denotes the position of the saturating irradiation, a thin arrow denotes the position where a noticeable NOE is expected. Whether a NOE is observable depends on the proton-proton distance, proton relaxation times and rotational correlation time of the protein. The predictions in this figure are based on previous NMR experiments with paramagnetic proteins $[14,15,26,27,34]$. Notice that in B no connectivities are expected when the irradiation is set at peaks $a$ and $b$.

$\beta$ the Bohr magneton, $T$ the absolute temperature, $\delta_{\mathrm{c}}$ the experimentally measured paramagnetic shift in $\mathrm{rad} / \mathrm{s}$ and $A$ the rotationally averaged (isotropic) dipolar interaction energy between the magnetic moment of the electrons and the nuclear magnetic moment. The solid lines in Fig. 5 represent least squares fits of the experimental data to Eq. 1, in which $J$ and $A$ were treated as adjustable parameters. The fits were obtained with a single value of $J$ and different values of $A$ for the individual signals. The values derived for $J$ from the best fits amount to $-2 J=298$ and $103 \mathrm{~cm}^{-1}$ for the chloridecontaining and chloride-free samples, respectively.

The peaks $\mathrm{a}^{1}-\mathrm{e}^{1}$ derive from a minor species in the $\mathrm{Cl}^{-}$containing sample which we have not further investigated. From the temperature dependence of the paramagnetic shifts a value of $-2 J=460 \mathrm{~cm}^{-1}$ is found for the exchange coupling in this species.

Finally we point out that the $T_{1}$ as well as the $T_{2}$ values in the chloride-free sample are substantially shorter than in the chloride-containing sample. The simplest explanation would be that in the former sample the electron spin correlation time is longer than in the latter sample. It thus appears that a reduction in the singlet-triplet spacing of the electronic energy levels is accompanied by an increase in the electron spin correlation time.

\section{Conclusion}

The results presented above provide the first unequivocal proof that the ligand sphere of the $\mathrm{Cu}_{2}$ site in tyrosinase contains six histidines, which all six coordinate by means of their $\mathrm{N} \varepsilon$ atoms. It is interesting to note that when corrected for the contribution from the minor species, the total peak intensity in the 15-50 ppm area (within an accuracy of \pm 2 protons) can be accounted for by the ring signals from six histidine ligands. Specifically there seems to be no sign of a protein-derived extra (bridging) ligand like a tyrosine or a cysteine side chain, an extra histidine or a peptidyl group.

We find that the size of the exchange coupling may vary appreciably depending on the species that is present in solution. In the absence of chloride we find $-2 J=103 \mathrm{~cm}^{-1}$, while the exchange coupling nearly triples in the presence of chloride $\left(-2 J=298 \mathrm{~cm}^{-1}\right)$, which indicates that chloride binds to the tyrosinase. It is not clear at this stage whether the increase in exchange coupling results from a direct binding of the chloride to the two $\mathrm{Cu}$ ions, or whether it is the result of a conformational change which affects the overlap between the two $\mathrm{Cu}$ (II) centers. An interesting possibility is that chloride acts as a bridging ligand, as has been previously proposed for the half-met derivative of Neurospora crassa tyrosinase and mollusc hemocyanin [35-37]. This is the subject of further investigation.

Although, on the basis of the purported similarity with the $\mathrm{Cu}_{2}$ site in hemocyanin, one is tempted to assume that the disposition of the ligands around the two copper ions in tyrosinase exhibits some symmetry, the NMR data do not confirm this. The signals of the histidine protons are dispersed over the whole 15-50 ppm range, each histidine having its own set of signals. Also the hydrogen exchange behavior of one of the NH peaks differs from that of the other five. An important point for future investigations will therefore be whether this asymmetry has mechanistic consequences; for instance, whether it reflects a different participation of the two $\mathrm{Cu}$ ions in the enzyme mechanism.

The present experiments have shown that even with a protein that is relatively large by NMR standards, a native paramagnetic dinuclear type-3 Cu-site can be studied in detail by paramagnetic NMR techniques. Further studies of substratebound and inhibitor-bound enzyme complexes are under way.

Acknowledgements: The authors are grateful to Prof. Dr. E. Katz for supplying them with a copy of the pIJ703 plasmid carrying the $S$. antibioticus tyrosinase gene and to Messrs Bristol-Meyers Squibb for the gift of a batch of thiostrepton. The authors gratefully acknowledge the assistance of Patricia de Kousemaeker and Kees Zaal in developing the purification protocol for tyrosinase. This work was performed under the auspices of the BIOMAC Research School of Leiden and Delft Universities and was supported by the Netherlands Foundation for Chemical Research (SON) with financial aid from the Netherlands Organisation for Scientific Research (NWO).

\section{References}

[1] Sánchez-Ferrer, Á., Rodríguez-López, J.N., García-Cánovas, F. and García-Carmona, F. (1995) Biochim. Biophys. Acta 1247, $1-11$. 
[2] Solomon, E.I., Sundaram, U.M. and Machonkin, T.E. (1996) Chem. Rev. 96, 2563-2605.

[3] Miller, K.I., Cuff, M.E., Lang, W.F., Varga-Weisz, P., Field, K.G. and van Holde, K.E. (1998) J. Mol. Biol. 278, 827-841.

[4] van Gelder, C.W., Flurkey, W.H. and Wichers, H.J. (1997) Phytochemistry 45, 1309-1323.

[5] Meakawa, M., Kitagawa, S., Munakata, M. and Masuda, H. (1989) Inorg. Chem. 28, 1904-1909.

[6] Holz, R.C. and Brink, J.M. (1994) Inorg. Chem. 33, 4609-4610.

[7] Mandal, P.K. and Manoharan, P.T. (1995) Inorg. Chem. 34, $270-277$.

[8] Lubben, L., Hage, R., Meetsma, A., Byma, K. and Feringa, B.L. (1995) Inorg. Chem. 34, 2217-2224.

[9] Satcher, J.H. and Balch, A.L. (1995) Inorg. Chem. 34, 33713373.

[10] Brink, J.M., Rose, R.R. and Holz, R.C. (1996) Inorg. Chem. 35, 2878-2885.

[11] Murthy, N.N., Karlin, K.D., Bertini, I. and Luchinat, C. (1997) J. Am. Chem. Soc. 119, 2156-2162.

[12] Himmelwright, R.S., Eickman, N.C. and Solomon, E.I. (1979) Biochem. Biophys. Res. Commun. 86, 628-634.

[13] Bertini, I., Bren, K.L., Clemente, A., Fee, J.A., Gray, H.B., Luchinat, C., Malmström, B.G., Richards, J.H., Sanders, D. and Slutter, C.E. (1996) J. Am. Chem. Soc. 118, 11658-11659.

[14] Dennison, C., Berg, A. and Canters, G.W. (1997) Biochemistry 36, 3262-3269.

[15] Salgado, J., Warmerdam, G., Bubacco, L. and Canters, G.W. (1998) Biochemistry 37, 7378-7389.

[16] Lin, L.Y., Park, H.I. and Ming, L.J. (1997) J. Biol. Inorg. Chem. 2, 744-749.

[17] Katz, E., Thompson, C.J. and Hopwood, D.A. (1983) J. Gen. Microbiol. 129, 2703-2714.

[18] Hopwood, D.A., Bibb, M.J., Chater, K.F., Kieser, T., Bruton, C.J., Kieser, H.M., Lydiate, D.J., Smith, C.P., Ward J.M. and Schrempf, H. (1985) Genetic Manipulation of Streptomyces: A Laboratory Manual, The John Innes Foundation, Norwich.
[19] Bernan, V., Filpula, D., Herber, W., Bibb, M. and Katz, E. (1985) Gene 37, 101-110.

[20] Bubacco, L., Vijgenboom, E., Gobin, C., Tepper, A.W.J.W., Salgado, J. and Canters, G.W. (1998) J. Mol. Catal. (in press).

[21] Lerch, K. and Ettlinger, L. (1972) Eur. J. Biochem. 31, 427437.

[22] Inubushi, T. and Becker, E.D. (1983) J. Magn. Reson. 51, 128133.

[23] Banci, L., Bertini, I., Luchinat, C. and Piccioli, M. (1990) FEBS Lett. 272, 175-180.

[24] Unger, S.W., LeComte, J.T.J. and La Mar, G.N. (1985) J. Magn. Reson. 64, 521-526.

[25] Thanabal, V., De Ropp, J.S. and La Mar, G.N. (1987) J. Am. Chem. Soc. 109, 7516-7525.

[26] Banci, L., Bertini, I., Luchinat, C., Piccioli, M., Scozzafava, A. and Turano, P. (1989) Inorg. Chem. 28, 4650-4656.

[27] Bertini, I. and Luchinat, C. (1996) Coord. Chem. Rev. 150, chapter 3.

[28] Bertini, I., Lanini, G., Luchinat, C., Messori, L., Monanni, R., Piccioli, M. and Scozzafava, A. (1985) J. Am. Chem. Soc. 107, 4391-4396.

[29] Banci, L., Bertini, I., Luchinat, C. and Scozzafava, A. (1987) J. Am. Chem. Soc. 109, 2328-2334.

[30] Canters, G.W. (1969) Thesis, University of Nijmegen.

[31] Canters, G.W. and de Boer, E. (1974) Mol. Phys. 27, 665-687.

[32] Van Broekhoven, J.A.M., Hendriks, B.M.P. and de Boer, E. (1971) J. Chem. Phys. 54, 1988.

[33] Canters, G.W., Hill, H.A.O. and Kitchen, N.A. (1984) J. Magn. Reson. 57, 1-23.

[34] Vila, A.J. (1994) FEBS Lett. 355, 15-18.

[35] Eickman, N.C., Himmelwright, R.S. and Solomon, E.I. (1979) Proc. Natl. Acad. Sci. USA 76, 2094-2098.

[36] Himmelwright, R.S., Eickman, N.C., LuBien, C.D. and Solomon, E.I. (1980) J. Am. Chem. Soc. 102, 5378-5388.

[37] Himmelwright, R.S., Eickman, N.C., LuBien, C.D., Lerch, K. and Solomon, E.I. (1980) J. Am. Chem. Soc. 102, 7339-7344. 